\title{
De la democracia representativa a la democracia directa
}

\section{Representative democracy and direct democracy}

\begin{abstract}
Clara Souto Galván Doctora en Derecho Constitucional Universidad Rey Juan Carlos Miembro de la Asociación de constitucionalistas en España

Recibido: 08/07/2013

Aprobado: 16/11/13

clara.souto@urjc.es

«¿Es la democracia, tal como la conocemos, el último logro posible en materia de gobierno ?¿No es posible dar un paso más hacia el reconocimiento y organización de los derechos del hombre?»

Henry David Thoreau
\end{abstract}

\section{RESUMEN}

La democracia representativa parecía un buen sistema de acción política y legislativa, mediante sufragio universal, los ciudadanos de nacionalidad española y mayores de 18 años, eligen libremente a los representantes, para que decidan por el pueblo, para que aprueben leyes y "velen" por el interés político, social y cultural. Pero el problema principal planteado es si pueden convertirse, a corto o medio plazo, o no en auténticas alternativas a la democracia representativa.

\section{PALABRAS CLAVE}

Democracia participativa, democracia directa, ciudadanía, sufragio

\section{ABSTRACT}

Representative democracy seemed a good system of political and legislative action. Through universal suffrage, the citizens of Spanish nationality older than 18 years, freely elect representatives to decide for the people. They make the laws and "watch" by the political, social and cultural interest. However, the main issue raised is whether it will become short or medium term, authentic alternative to representative democracy.

\section{KEYWORD}

Participatory democracy, direct democracy, citizenship, suffrage

\section{INTRODUCCIÓN}

La democracia representativa parecía un buen sistema de acción política y legislativa, mediante sufragio universal, los ciudadanos de nacionalidad española y mayores de 18 años, eligen libremente a los representantes, para que decidan por el pueblo, para que aprueben leyes y "velen" por el interés político, social y cultural. Por su parte, como acertadamente se ha dicho:

Se ha limitado a actuar a través de la celebración de elecciones periódicas más o menos competitivas, con una defensa formal del pluralismo, y la creación de un marco normativo configurador de condiciones más o menos adecuadas para un pluralismo político 
aceptable en aquel momento, interpretando que no eran necesarias otras series de manifestaciones, pues su presencia estaba absolutamente consolidada (Álvarez, 2013).

La democracia representativa y la democracia directa fueron ya objeto de un importante debate teórico en la Asamblea Constituyente de la revolución francesa, siendo posteriormente también analizadas por los grandes teóricos del constitucionalismo clásico. Posteriormente, la defensa de las instituciones de democracia directa corrió a cargo de las fuerzas políticas más conservadoras e incluso fascistas (Napoleón III, De Gaulle, el propio Franco, etc....), siendo en las Cortes Españolas "constituyentes" estas fuerzas conservadoras las más acérrimas defensoras de las mismas (Fraga). Finalmente, la propia Constitución, a diferencia de otros textos constitucionales, opta claramente por el sistema representativo, configurando unas instituciones de democracia directa 0 semi-directa muy poco significativas y con un valor muy complementario.

Pero esta confianza depositada en la clase política, paulatinamente se ha erosionado, ya que el comportamiento de los representantes no siempre está presidido por el interés general y, con frecuencia, prevalece su interés personal o partidario, lo que ha dado lugar a una creciente desafección popular. En gran medida la teoría de la representación construida por los revolucionarios franceses, y que se continúa manteniendo sustancialmente en la actualidad, es, como ya señala el propio Kelsen (1979), una auténtica tautología, pues los representantes únicamente se representan a sí mismos. (pp. 303305)

Como consecuencia de esta crisis económica e institucional, surgen una serie de soluciones fácticas ${ }^{1}$; acuerdos de grupos no institucionales

1 ¿Qué propone el Movimiento 15M? El programa político de los indignados: El 15M es un movimiento apartidista y asindicalista que se organiza en torno a asambleas descentralizadas por los barrios de las ciudades de toda España. Como ellos mismos dicen: "Vamos despacio porque vamos lejos". Como resultado del consenso alcanzado durante la Asamblea celebrada el día 20 de mayo de 2011 en ACAMPADA SOL, y como resultado de la recopilación y síntesis de las miles de propuestas recibidas a lo largo de estos días, se ha elaborado una primera relación de propuestas. Recordamos que la Asamblea es un proceso abierto y colaborativo. Esta lista no debe entenderse como cerrada. Propuestas aprobadas en la Asamblea de hoy día 20 de mayo de 2011 en ACAMPADA SOL. • Cambio de la Ley Electoral para que las listas sean abiertas y con circunscripción única. La obtención de escaños debe ser proporcional al número de votos. •Atención a los derechos básicos y fundamentales recogidos en la Constitución como son: derecho a una vivienda digna, articulando una reforma de la Ley Hipotecaria para que la entrega de la vivienda en caso de impago cancele la deuda; sanidad pública, gratuita y universal; libre circulación de personas y refuerzo de una educación pública y laica. -Abolición de las leyes y medidas discriminatorias e injustas como han calificado la Ley del Plan Bolonia y el Espacio Europeo de Educación Superior, la Ley de Extranjería y la conocida como Ley Sinde. •Reforma fiscal favorable para las rentas más bajas, una reforma de los impuestos de patrimonio y sucesiones. Implantación de la Tasa Tobin, que grava las transferencias financieras internacionales y supresión de los paraísos fiscales. •Reforma de las condiciones laborales de la clase política para la abolición de sus sueldos vitalicios, así como que los programas y las propuestas políticas tengan carácter vinculante. • Rechazo y condena de la corrupción. Que sea obligatorio por la Ley Electoral presentar unas listas libres de imputados o condenados por corrupción. - Medidas plurales con respecto a la banca y los mercados financieros en cumplimiento del artículo 128 de la Constitución, que determina que "toda la riqueza del país en sus diferentes formas y sea cual fuere su titularidad está subordinada al interés general". Reducción del poder del FMI y del BCE. Nacionalización inmediata de todas aquellas entidades bancarias que hayan tenido que ser rescatadas por el Estado. Endurecimiento de los controles sobre entidades y operaciones financieras para evitar posibles abusos en cualquiera de sus formas. •Desvinculación verdadera entre la Iglesia y el Estado, como establece el artículo 16 de la Constitución. -Democracia participativa y directa en la que la ciudadanía tome parte activa. Acceso popular a los medios de comunicación, que deberán ser éticos y veraces. • Verdadera regularización de las condiciones laborales y que se vigile su cumplimiento por parte de los poderes del Estado. • Cierre de todas las centrales nucleares y la promoción de energías renovables y gratuitas. Recuperación de las empresas públicas privatizadas. Efectiva separación de los poderes ejecutivo, legislativo y judicial. Reducción del gasto militar, cierre inmediato de las fábricas de armas y un mayor control de las fuerzas y cuerpos de seguridad del Estado. • Recuperación de la Memoria Histórica y de los principios fundadores de la lucha por la Democracia en el Estado. • Total transparencia de las cuentas y de la financiación de los partidos políticos como medida de contención de la corrupción política. http://www.movimiento15m.org/

Por otro lado, se encentran estudios a esta situación, como la de Daniel Innerarity, catedrático de Filosofía Política y Social, en su conferencia "La política después de la indignación. Reflexiones en torno al 15-M, la desconfianza ciudadana y la transformación de la democracia", Daniel Innerarity, explicó que el movimiento de los indignados en España no es revolucionario, sino que pretende estimular a la opinión pública. Añadió que los tiempos venideros son de desilusión democrática, por el desencanto existente con la clase política (...)http://www.ifuturo.org/es/actividades/conferencia_ficha.asp?id=1474\&accion=ficha\&gclid=COyqtee kbsCFQkEwwodRxAA4A 
tratan de sustituir la democracia representativa por la democracia directa. Reivindican que estos acuerdos, a través de la vía legal y constitucional, sean reconocidos y se tomen en cuenta a la hora de tomar decisiones que afectan al pueblo español. La legitimidad democrática de todas estas actuaciones es difícilmente cuestionable. Pero el problema principal planteado es si pueden convertirse, a corto o medio plazo, o no en auténticas alternativas a la democracia representativa.

\section{INSTITUCIONES DE LA DEMOCRACIA REPRESENTATIVA Y DIRECTA}

La democracia directa es un sistema de gobierno que prescinde de todo órgano mediato y representativo, en el que las decisiones políticas se adoptan por los ciudadanos reunidos en Asamblea (Lawrence, 2003). El teórico clásico de la democracia directa es Rousseau, que la defiende como la única forma de democracia posible, basándose en tres postulados: El pueblo no se representa más que a sí mismo, las leyes han de ser directa emanación de la voluntad popular, por lo que cualquier órgano o cuerpo intermedio constituye una distorsión de dicha voluntad, y la libertad sólo se alcanza como resultado de la identificación con la voluntad general $\mathrm{y}$, por lo tanto, es necesario que las leyes, como manifestación de la soberanía y plasmación de dicha voluntad general, sea adoptada directamente por Ios propios ciudadanos. En este sentido Rousseau afirma que en los sistemas como Inglaterra, en la que existía un Parlamento cuyos miembros eran elegidos por sufragio, el ciudadano es sólo libre en el momento en que elige a su representante. Una vez elegido éste, el ciudadano vuelve a ser esclavo (Rousseau, 1969).

Sin embargo, a partir de la Revolución francesa, "se va a pasar del ámbito teórico al práctico, la democracia directa del ágora ateniense es inviable, por lo que se plantea la cuestión de qué papel se ha de dar a la participación directa" (Carbajal, 2008, p.4059). La Declaración de Derechos del Hombre y del Ciudadano recoge los dos tipos de participación, tanto la directa, como la representativa.

Ante esta situación los grandes teóricos empezarán a decantarse por uno u otro sistema, priorizando el sistema representativo, reduciendo la democracia directa a unos pocos actos dentro del marco de la institución representativa, lo que Duguit (1984) consideró como semi-directa y democrática. A finales del siglo XIX se produce un claro asentamiento del sistema liberal representativo.

El asentamiento definitivo del Estado constitucional
contemporáneo, la extensión del Estado de Bienestar,
la posición de los poderes públicos y la primacía del
Poder Ejecutivo, y los nuevos planteamientos entre
la sociedad civil y los poderes públicos, hacen que
las clásicas instituciones de democracia directa o
semi-directa (referéndum, la iniciativa popular...),
se conviertan en puramente instrumentales o
complementarias (Álvarez, 2010: 90-92).

Lo que plantea la cuestión de si realmente deben dejar de ser complementarias o si por el contrario, es necesario que se mantenga esta complementariedad 0 un mayor uso por parte de la ciudadanía. ${ }^{2}$

La Constitución española de 1978 ha optado por la democracia representativa, y para conservar el Estado Social y Democrático de Derecho del que disfrutamos, la Constitución española propugna como valores superiores del ordenamiento jurídico "la libertad, la justicia, la igualdad y el pluralismo político". En el marco de este reconocimiento de valores se ha ido desarrollando la legislación española, función que han ejercido las Cortes Generales pues representan al pueblo español, se les ha atribuido la legitimidad para que ejerzan la potestad legislativa, controlen la acción del gobierno y las demás competencias que les atribuya la Constitución (artículo 66 de la CE).

De la soberanía nacional, que reside en el pueblo español (art.1.2) emanan los poderes del Estado $y$, entre ellos, la función legislativa atribuida a las Cámaras legislativas (Congreso de los Diputados

2 El prof. Michele Della Morte (Universidad del Molise), enfoca su contribución en el derecho a decidir haciendo referencia al alcance, la titularidad, el objeto y el ejercicio del mismo, así como, en los límites que la democracia constitucional le impone. 
y Senado), así como la dirección de la política interior y exterior, y la función ejecutiva y la potestad reglamentaria atribuida al Gobierno (art. 97). La justicia también emana del pueblo y se administra en nombre del Rey por jueces y magistrados integrantes del poder judicial (art. 117.1). Este conjunto de la vinculación de la soberanía nacional con el pueblo español se cierra con el derecho de los ciudadanos de participar en los asuntos públicos, directamente 0 por medio de representantes, libremente elegidos en elecciones periódicas por sufragio universal (art. 23).

Junto a la institución de la "democracia representativa” (Mills, 1991) o la participación política a través de representantes, la elaboración de una nueva "política normativa en materia de participación ciudadana" parece exigir una atención a nuevas instituciones de democracia directa (consultas populares), mejorar las ya existentes (iniciativa legislativa popular), pero sobre todo incidir en la denominada "democracia participativa", consagrando un conjunto de derechos y prestaciones que ofrecen a la ciudadanía la posibilidad de conocer, incidir, participar e incluso contribuir a transformar la realidad social, económica y política (STC 136/1999). Se trataría de "facilitar cauces paralelos- en algunos casos, con la posibilidad de mejorar alguno que ya existe-, a los mecanismos de democracia representativa que contribuyen a la formación de la voluntad del poder público y a conformar el contenido de las políticas públicas" (Tur Ausina, 2010).

Por tanto, una alternativa al sistema representativo (Haskell, J. 2001) sería la democracia participativa (Álvarez, 2010: 91-92) lo que supondría que la participación ciudadana en los asuntos públicos pudiera realizarse mediante otros cauces; por un lado, a través del instituto de representación, mediante las instituciones clásicas de democracia directa recogidas en nuestra Constitución (el referéndum y la iniciativa popular) y por último, a través de nuevas formas de participación directa, entre las cuales se encuentran las consultas populares, que debe ser considerada como una manifestación del artículo 23.1, es decir, como una participación ciudadana en los asuntos públicos.
Hay autores que señalan tres mecanismos de democracia directa; por un lado, la revocación de mandato, que es la menos utilizada, es una variante invertida de la elección de representantes: a partir de una petición popular que debe reunir ciertos requisitos (un número determinado de firmas, por ejemplo), se somete a la aprobación de los votantes la permanencia en su cargo o la remoción de un representante electo antes del plazo determinado por la ley. Según señala el diccionario de la Real Academia de la lengua Española "la revocación consiste en anular o dejar sin efecto una concesión, un mandato o una resolución", por lo que la revocación de mandato representativo otorgado por los electores, les permitirá destituir de un cargo público antes de que finalice el período para el que fue elegido, "se basa en el elemental principio de quien tiene la capacidad para elegir la tiene también para cesar y, por tanto, para dejar sin efecto su decisión final"(Arnaldo,2008:1190).

La Constitución española de 1978 determina en el art. 67.2 que "los miembros de las Cortes Generales no estarán ligados por mandato imperativo" por 10 que la relación entre electo y elegido no se regirá por la revocación de mandato, al contrario, esta relación de representación es irrevocable hasta que finalice el período por el que fue elegido. "Sin embargo la revocatoria de mandato subsiste en algún cantón suizo y en algún Estado norteamericano como mecanismo para la retirada de la confianza del cuerpo electoral a sus representantes, aunque su uso es excepcional" (Arnaldo, 2008: 11491). Por otro lado, el referéndum, que como se establecía con anterioridad, implica la participación del pueblo en el proceso legislativo, por medio de la consulta directa, y por último, la iniciativa popular que podría decirse se trata de una subcategoría del referéndum, en la cual la propuesta sometida a votación tiene su origen en el electorado.

La iniciativa legislativa viene regulada en el artículo 87 de la Constitución española y establece que "corresponde al Gobierno, al Congreso y al Senado de acuerdo con la Constitución y los reglamentos de las Cámaras", a continuación, en el apartado segundo, regula la iniciativa legislativa autonómica 
y en el último apartado, la iniciativa legislativa popular, que establece que:

Una ley orgánica regulará las formas de ejercicio y requisitos de la iniciativa popular para la presentación de proposiciones de ley, en la que se exigen no menos de 500.000 firmas acreditadas. No procederá dicha iniciativa en materias propias de ley orgánica, tributarias 0 de carácter internacional, ni en lo relativo a la prerrogativa de gracia.

Sin embargo, en España, además de los referéndums y la iniciativa popular, en el ámbito local regula otro mecanismo de democracia directa, como es el concejo abierto, reconocido en el artículo 140 de la Constitución española, se trata de una institución de origen medieval que se encuentra en la actualidad regulada en el artículo 29 de la Ley de Bases del Régimen Local. En el régimen de concejo abierto, el gobierno y la administración municipal corresponden a un alcalde y a una asamblea vecinal compuesta por todos los electores. De conformidad con la Ley de Bases, funcionan en régimen de concejo abierto "Ios municipios de menos de 100 habitantes, los que tradicionalmente cuenten con este régimen, y todos aquellos que por su localización geográfica, la mejor gestión de los intereses municipales 0 cualquier otra circunstancia lo hagan aconsejable", en estos casos, continúa el art. 29 LBRL, "Ios alcaldes de las corporaciones de municipios podrán convocar a sus vecinos a Concejo Abierto para decisiones de especial trascendencia para el municipio. Si así lo hicieren deberán someterse obligatoriamente al criterio de la Asamblea vecinal constituida al efecto".

Del estudio de estos mecanismos de democracia directa en el estado español se concluye la ausencia a nivel nacional (que no autonómico) ${ }^{3}$ de una legislación de participación política donde se consulten estas instituciones, salvo en el caso de las leyes sectoriales de medio ambiente, supone un interrogante en el reconocimiento de las mismas. Ante esta ausencia, las Comunidades Autónomas han iniciado un proceso legislativo en el que proponen mayor participación de los ciudadanos, de este modo Valencia aprobó en 2008 la Ley 11/2008 de participación ciudadana y "Ileva a cabo una regulación de estas figuras con pretensión de globalidad" (Castellá J. 2009), a su vez, Extremadura ha aprobado la Ley 4/2013, de 21 de mayo, de Gobierno Abierto de Extremadura, en la cual el título III define los conceptos de participación y colaboración ciudadana, y lo que es más importante, establece los mecanismos para conseguirlo: "El Gobierno de Extremadura se compromete a impulsar la participación llevando a cabo las acciones de promoción y difusión necesarias para que los ciudadanos conozcan las oportunidades de participar y los derechos que les ofrece esta ley".

Otras Comunidades autónomas como Andalucía y Cataluña, todavía se encuentran en el procedimiento de elaboración. La Ley Andaluza de Participación Ciudadana es uno de los compromisos recogidos en el Acuerdo por Andalucía del actual gobierno. El propósito que persigue es regular la participación ciudadana definida como un derecho político. Esta ley pretende proteger este derecho, promoverlo y desarrollarlo. Y Cataluña ya ha elaborado la Proposición de Ley de Consultas Populares no Refendarias y de Participación Ciudadana.

De este modo, se está ante la presencia de un nuevo marco legislativo, el cual hace un llamamiento a las figuras de democracia directa y participativa desde el ámbito autonómico, lo que debería plantearse el Estado es la elaboración de una legislación básica sobre participación ciudadana, pues ante la desafección ciudadana y la crisis tanto económica como institucional y autonómica, podría ayudar a homogeneizar la situación actual.

\section{2. ¿REFERÉNDUM: MECANISMO DE DEMOCRACIA DIRECTA?}

A largo de la historia del constitucionalismo español no se incluyó en ningún texto fundamental español la necesidad de ratificación popular para modificarlo, desde la Constitución de Bayona de 1808 hasta la de la Segunda República de 1931, la facultad

3 Ley 4/2010, de 17 de marzo, de consultas populares por vía de referéndum (Ley vigente aunque impugnada por el Gobierno de Rodríguez Zapatero ante el Tribunal Constitucional y pendiente de sentencia) 
de reforma se reconocía a las Cortes a través del procedimiento legislativo ordinario como es el caso de las Constituciones de 1937 y 1876, en otros se establecían unos trámites agravados, como en las Constituciones de 1812 y 1869 , pero en ninguna de ellas, se preveía la consulta directa al pueblo.

En España, el referéndum en el proceso constituyente, no contempló el referéndum legislativo abrogativo y la restricción de los sujetos legitimados para solicitar la celebración de un referéndum, regulando sólo en el artículo 92 el referéndum, que calificaron de "consultivo", aquel que se plantearía sobre decisiones políticas de especial trascendencia (Araujo, 1986). Todo ello, porque había un claro rechazo a la idea que se había formado del referéndum en la época de régimen franquista. ${ }^{4}$

Por este motivo, cuando se llevó a cabo la aprobación del referéndum en el proceso constituyente se establecieron una serie de restricciones, como la limitación de dos tipos de referéndum y que la facultad de solicitar la celebración de un referéndum se restringiría a la figura del Presidente del Gobierno.

Esto supondrá la aprobación del referéndum en el proceso constituyente con un carácter muy limitado, pues en el debate constituyente quedó patente la desconfianza hacia las técnicas de democracia directa. (López, 2002)

En el marco del Derecho comparado son muchas las Constituciones que incorporan el referéndum a su proceso de reforma (Hamon, 1995). Entre ellas, el art. 88 de la Constitución danesa de 1953, el art. 89 de la Constitución francesa de 1958, los arts. 46 y 47 de la Constitución irlandesa de 1937 y el art. 138 de la Constitución italiana de 1947, el art. 51,7 de la Constitución de Luxemburgo de 1868, el art. 22 de la Constitución de Finlandia de 1919, en 1988 se reformó en la Constitución austriaca el referéndum en el art. 49 b.
En el proceso revolucionario francés, ya establecía Condorcet que "no puede haber Constitución que no haya sido aceptada por el pueblo", se reconocía, por tanto, por primera vez la participación popular directa en el proceso constituyente (Aguiar De Luque, 1997).

En Francia la noción de referéndum (Morel, 1996) consultivo ha sido poco estudiada. Sin duda, se plantea en la mayoría de los manuales de derecho constitucional, como uno de los posibles tipos de referéndum, como el referéndum legislativo, el referéndum abrogativo ${ }^{5}$ y el constitucional. Debemos partir del artículo 3 de la Constitución francesa que establece que "la soberanía nacional pertenece al pueblo, quien la ejerce por medio de sus representantes y por la vía del referéndum", en este caso, en comparación con las constituciones antes estudiadas, se comprueba que el referéndum ocupa un lugar más privilegiado y que realmente se utiliza como instrumento de democracia directa, a pesar de que en el mismo artículo se manifiesta una democracia representativa, creando una versión conjunta de ambos tipos de democracia en un mismo artículo. Denquin, (1976) pone de relieve la importancia de que el referéndum -y, en general, todos los institutos de democracia semidirecta- sea un fin en sí mismo y no un medio, lo que alteraría su función en sentido antidemocrático.

En Italia el referéndum se utiliza como método principal de la democracia directa, expresado por la mayoría de la doctrina italiana "como la posibilidad de los ciudadanos de expresarse directamente sobre decisiones políticas, sin la intermediación de los representantes" (Groppi, 2010). Según el profesor Olivetti (2007), el único instrumento de democracia directa, de hecho, es el referéndum, como modalidad de consulta del cuerpo electoral productiva de efectos jurídicos, pero destinados para

4 Franco para aparentar ante la Comunidad Europea e internacional que adoptaba las decisiones que se planteaban, aprobó el referéndum obligatoria regulado en el art. 10 de la Ley de Sucesión en la Jefatura de Estado de 1947 y lo preveía para modificar o derogar las leyes fundamentales, en el que se establecía que "para derogarlas o modificarlas (a las Leyes Fundamentales) será necesario, además del acuerdo de las Cortes, el referéndum de la Nación'”. Por su parte, el artículo 7 de la Ley Orgánica del Estado de 10 de enero de 1967 establecía que "corresponde, particularmente, al Jefe del Estado: (...) c) Someter a referéndum de la Nación los proyectos de ley a que se refiere el párrafo segundo del artículo diez de la Ley de Sucesión'”.

5 El término abrogativo, se utiliza sobre todo en Italia, donde los votantes, votan a favor o en contra de la derogación de un texto. 
funcionar sólo de manera excepcional, mientras que las Constituciones y las leyes electorales regulan las elecciones como instrumento de la vida política ordinaria de los distintos países. ${ }^{6}$

Otras posturas opuestas, como la del profesor Luciani (2008), establece que:

No sólo el referéndum no es una institución de democracia directa, sino que parece históricamente y lógicamente discordante con esta forma de gobierno. Históricamente, porque la institución referendaria nace y se desarrolla cuando se consolidan asambleas representativas cuyos miembros, como máximo, se tienen que dirigir a los representados para informar sobre las determinaciones asamblearias (y se dirigen ad referendum, justamente)

Sino que debe considerarse como una institución (bien que -obviamente- no necesaria) del régimen representativo. ${ }^{7}$

Existe una gran variedad de definiciones dadas por la doctrina italiana sobre el referéndum, en la línea del profesor Luciani establece que "se trata de una votación popular de contenido no electoral, que se distingue claramente de otras formas de pronunciamiento popular con las cuales a menudo se confunde indebidamente".

El sistema constitucional italiano constituye una excepción en un panorama de marginalización de los referendos, lo que resulta evidente no sólo en las disposiciones constitucionales y legislativas del referéndum, sino también en la práctica del mismo como instrumento de democracia directa. (Olivetti, 2007:149)

\section{REFERÉNDUM, PLEBISCITO Y CONSULTA POPULAR}

La Real Academia Española define el referéndum como "Procedimiento jurídico por el que se someten al voto popular leyes 0 actos administrativos cuya ratificación por el pueblo se propone". Este procedimiento jurídico tiene su origen en las prácticas de la República Romana, en la que los ciudadanos comunes, votaban una ley a petición del tribuno de la plebe. En la actualidad, el referéndum es considerado como una manifestación de la democracia constitucional ${ }^{8}$, en la cual, mediante la ampliación del sufragio y el libre acceso a los cargos públicos, la totalidad del pueblo organizado en cuerpo electoral participa en el proceso de poder, lo que hace indirectamente al elegir a sus representantes y directamente por medio del referéndum y el plebiscito.

En torno al referéndum existe una experiencia relativamente amplia en los ordenamientos de nuestro entorno, de la que se extrae la conclusión "de que no siempre existe -ni ha existido- una identidad absoluta en su caracterización general 0 en sus diferentes modalidades, así como en la identificación de este instituto frente a otras figuras próximas" (López, 2009:202-240). Formas similares pueden recibir, en ocasiones, denominaciones diferentes, considerándose en unos países como referéndum en sentido estricto lo que en otros países se identifica como otro tipo de figuras similares 0 afines $^{9}$ (especialmente, el plebiscito).

La voz plebiscito tiene su origen en el término latino plebiscitum (Ilamada o convocatoria a la "plebe"-

6 En el desarrollo del referéndum en el contexto europeo el profesor Olivetti enmarca a estados como Alemania, Reino Unido, España e incluso Francia como países que conciben el referéndum como un instrumento para resolver solamente cuestiones políticas y constitucionales, aunque la ideología de la Constitución de la V República -basada en una reelaboración de la tradicional doctrina de la soberanía nacional en favor de la soberanía popular. parece abrir la vía a un uso más amplio e incisivo del mecanismo del referéndum.

7 También en Luciani, M., (2005:cap.l). El autor subraya que es difícil dar una definición compartida de referéndum aunque lo identifica con un pronunciamiento popular por medio de votación de los ciudadanos sobre cuestiones jurídicamente relevantes, y lo distingue de otras formas de pronunciamiento popular como las deliberations "expresión de la democracia deliberativa, o como aquí se sostiene, participativa) y también de las iniciativas populares (con votación final del cuerpo electoral)"

8 Como antes se ha comentado (p.3) también fue utilizado por los regímenes autoritarios.

9 El profesor Castellà hace un interesante estudio a nivel de derecho extranjero subnacional, en su artículo "Consultas populares no referendarias en Cataluña. ¿Es admisible constitucionalmente un tertium genus entre el referéndum e instituciones de participación ciudadana?". En el cual plantea el caso de Quebec, donde referéndum y consulta popular se utilizan como sinónimos. La Loi sur 
al pueblo). El Diccionario de la Real Academia de la Lengua Española define el "plebiscito" como la "consulta que los poderes públicos someten al voto popular directo para que apruebe o rechace una determinada propuesta sobre soberanía, ciudadanía, poderes excepcionales, etc."

El plebiscito es objeto de profundas críticas desde la óptica democrática, en la medida en que "altera los principios de funcionamiento del sistema democrático, y lo dota de un fuerte significado personalista que lo convierte en un instrumento con grandes riesgos de degeneración autoritaria" (Chiappetti, 1983:945). La doctrina se encuentra dividida en lo referente al significado de referéndum y plebiscito, una parte de la doctrina le otorga un idéntico significado ${ }^{10}$, sin embargo, vamos a matizar una serie de aspectos que diferencian ambos conceptos.

Las características que diferencian al referéndum del plebiscito ${ }^{11}$, ha puesto de relieve que una $y$ otra figura comparten el elemento sustancial la convocatoria al cuerpo electoral para que se pronuncie, afirmativa o negativamente, a través del voto-; y ha puesto de relieve, igualmente,

Que una de las teorías tradicionales de diferenciación entre una y otra figura radica en la vinculación 0 desvinculación a la adopción de un acto -jurídico o político- por parte del sistema institucional de la democracia representativa, así como la existencia 0 ausencia de una regulación previa de la misma por parte de las normas sobre la constitución del ordenamiento (Chiappetti, 1983:945).

En relación al contenido, la doctrina fundamentalmente alemana, utiliza los términos referéndum y plebiscito para distinguir si la consulta opera dentro del proceso de creación, modificación o derogación de las leyes, para lo cual el término más adecuado es el referéndum; 0 si se trata de una decisión política no relacionada directamente con un acto legislativo, en cuyo caso se trataría de un plebiscito (Álvarez, 2013)

Por lo que se refiere a la forma, la distinción afectaría a cuestiones tales como el cuerpo electoral (Biscaretti, 1965:425) ${ }^{12}$ o los destinatarias afectados, el procedimiento establecido y sus garantías, en el sentido de si son las inherentes o no al derecho de sufragio activo.

A este respecto señala la doctrina, que la participación popular a través del referéndum se encuentra más solemnizada y afecta al conjunto de la ciudadanía, cosa que no tiene por qué suceder con las formas de consultas populares, como las encuestas, los sondeos, los fórums, los espacios de debate, etc., donde la ciudadanía también puede expresar sus opiniones, aunque sin tener la misma trascendencia política.

En este sentido la jurisprudencia del Tribunal Constitucional en su STC 103/2008, de 11 de septiembre define el referéndum como "una especie del género "consulta popular" con la que no se recaba la opinión de cualquier colectivo sobre cualesquiera asuntos de interés público a través de cualesquiera procedimientos, sino aquella consulta cuyo objeto se refiere estrictamente al parecer del cuerpo electoral respecto a aquellos asuntos públicos propios del artículo 23 de la $\mathrm{CE}$, y que se sustancia a través del correspondiente cuerpo electoral".

El Tribunal Constitucional en esta sentencia precisó la relación entre referéndum y consulta

la consultation populaire (LRQ, ch. C-64.1) regula sólo el referéndum en el que el gobierno puede preguntar sobre una cuestión aprobada por la Asamblea Nacional o sobre un proyecto de ley aprobado por la Asamblea y antes de su sanción (art. 7). Esta ha sido la ley seguida en los referendos llevados a cabo desde 1980 en relación con el status de Quebec de la Federación.

10 En esta línea, Santamaría Pastor, tras poner de manifiesto que "conforme a la distinción clásica en la doctrina constitucionalista, el nombre de referéndum es sólo aplicable a las consultas populares que versan sobre la aprobación de textos legales", entiende que no cabe establecer ninguna distinción relevante y se trata, en todo caso, de una cuestión meramente académica, en Santamaría Pastor, J.A. (1985).

11 Varios autores señalan las diferencias entre referéndum, plebiscito y la iniciativa popular; como son: Aguiar de Luque, L. (1986). 12 Consideraba que el término plebiscito se debería utilizar para el pronunciamiento del cuerpo electoral en relación a un hecho, acto político o medida de gobierno (en particular, cuestiones de carácter territorial y asuntos relativos a la forma de gobierno), reservando la denominación "referéndum" para la "manifestación del cuerpo electoral respecto a un acto normativo" 
popular. En este sentido, es importante incidir en el tema de las consultas populares, figura que es necesario diferenciar, en el marco de este estudio, desde una pluralidad de puntos de vista, de otras instituciones de democracia semidirecta (como pudiera ser el referéndum) "para insertarla en el funcionamiento que caracteriza a los sistemas de gobierno representativos como el nuestro, donde todos los operadores jurídicos le han atribuido un papel de preeminencia, mostrándose reacios hacia las instituciones de democracia directa" (Álvarez, 2013: 94).

Es más, dado el "carácter restrictivo con que han sido configuradas las instituciones clásicas de democracia directa, lo cual no puede ser corregido sustancialmente si no es a través del mecanismo de reforma constitucional, se hace preciso una potenciación dogmática de estas nuevas formas de participación, deslindándolas claramente de las clásicas ya conocidas, e intentando hacer que las mismas se conviertan, de forma sectorial o general, en un complemento indispensable del propio sistema representativo, y no simplemente en un mero apéndice de aquel" (Álvarez, 2013: 89).

Hay varios aspectos importantes a destacar en el análisis de esta sentencia ${ }^{13}$ y que permite realizar una interpretación más profunda en relación con la aplicación de la misma:

El primero es de carácter competencial, en la medida en que se considera que la 'consulta', a pesar de su nombre, no es otra cosa que un referéndum, para cuya convocatoria la Comunidad Autónoma carecería de competencia. En los antecedentes de la Sentencia se incorpora, junto a los indicados, un nuevo argumento por el que se niega, igualmente, que la 'consulta' sea un referéndum. Establece la distinción entre consulta popular y referéndum en términos de género y especie, y no por los efectos de la consulta, ya que son posibles los referendos consultivos (art. $92 \mathrm{CE}$ ).
La sentencia enumera los elementos que permiten identificar un referéndum y distinguirlo de las otras consultas populares: "aquella consulta cuyo objeto se refiere estrictamente al parecer del cuerpo electoral conformado y exteriorizado a través de un procedimiento electoral, esto es basado en un censo, gestionado por Administración electoral y asegurado con garantías jurisdiccionales específicas". En cambio las demás consultas populares son aquellas en que "se recaba la opinión de cualquier colectivo sobre cualesquiera asuntos de interés público a través de cualesquiera procedimiento" (FJ 2).

Además de estas diferencias hay que matizar que "el referéndum, en el ordenamiento constitucional español, forma parte del contenido del derecho fundamental de participación directa del art. 23.1 CE, cosa que no sucede con las demás consultas". (Castellà, 2013: 121,155). En definitiva, "se ha centrado el análisis sobre la existencia 0 no de referéndum en la concurrencia acumulativa de los tres elementos citados: sujeto convocado (el cuerpo electoral), procedimiento para llevarlo a cabo (el electoral) y garantías administrativas y jurisdiccionales propias de éste. De modo que, se concluye, si falta alguno de ellos ya no estamos ante un verdadero referéndum" (Castellà, 2013: 132).

En este sentido, el TC:

Distingue la participación política de la participación en general, y precisa que el referéndum es un instrumento de participación directa de los ciudadanos de naturaleza estrictamente política, manifestación del derecho fundamental de participación política contenido en el artículo 23.1 de la Constitución; es decir, es "una forma de democracia directa" y no una mera manifestación de la participación, en general, de las que difiere tanto en su justificación u origen como en su eficacia jurídica. Las formas de participación política directa son modalidades de la democracia política, manifestación de una voluntad

13 Tribunal Constitucional, Sentencia núm. 103/2008 de 11 septiembre, RTC\2008\103, Recurso de inconstitucionalidad interpuesto por el Presidente del Gobierno en relación con la Ley del Parlamento Vasco 9/2008, de 27 junio, de convocatoria y regulación de una consulta popular al objeto de recabar la opinión ciudadana en la Comunidad Autónoma del País Vasco sobre la apertura de un proceso de negociación para alcanzar la paz y la normalización política: convocatoria de referéndum que compete al Estado: "Estimación: inconstitucionalidad y nulidad de la Ley impugnada". 
general -y no particular o colectiva, como las otras formas de participación-, en la medida en que son imputables al cuerpo electoral. ${ }^{14}$

Su función, por tanto, señala el TC, no es recabar "la opinión de cualquier colectivo sobre cualesquiera asuntos de interés público a través de cualesquiera procedimientos, sino aquella consulta cuyo objeto se refiere estrictamente al parecer del cuerpo electoral", es decir, expresivo de la voluntad del pueblo -tal y como se recogía en la STC 12/2008-.

\section{CONCLUSIONES}

La crisis política, económica e institucional ha puesto al descubierto la situación de desafección política de la ciudadanía. Esta circunstancia ha dado lugar a la revisión de cuestiones básicas de la organización política y, en concreto, de la democracia representativa y de los mecanismos de la democracia directa: ¿Cuál es el significado genuino de la expresión: "la soberanía nacional reside en el pueblo español"? ¿Cuántas decisiones de especial trascendencia política se han sometido a referéndum nacional?.

La reflexión sobre estas cuestiones conduce necesariamente a la valoración del vigente sistema político y a la necesidad de afrontar su reforma 0 actualización, de tal manera que en el mismo, tengan cabida efectiva la democracia representativa y la democracia directa. Es decir, hacer realidad una mayor implicación de los ciudadanos en el quehacer político a través de la utilización de los mecanismos de democracia directa o la puesta en práctica de un nuevo concepto que empieza a tomar forma en la legislación autonómica: la democracia participativa.

Tomando como punto de referencia la jurisprudencia del Tribunal Constitucional a lo largo de este estudio, hemos intentado explicitar el concepto de estos mecanismos de democracia directa, diferenciando el referéndum de la consulta popular, del plebiscito, del concejo abierto para que no haya lugar a equívocos innecesarios.
El Referéndum en todas sus modalidades, aconseja la necesidad de reformar la Constitución para que se regule una nueva modalidad, un referéndum similar al derogatorio que permitiera a los ciudadanos tomar la iniciativa para decidir sobre la derogación parcial o total de una ley.

El escaso uso en España de los instrumentos de participación ciudadana ha dado lugar al cuestionamiento del referéndum, así como de los políticos que no han hecho uso del mismo, provocando el escepticismo de la ciudadanía y la aparición de una nueva terminología: la desafección ciudadana.

El presente estudio es sólo una propuesta más que se suma a una larga lista de reformas que se han formulado por los especialistas para actualizar la Constitución y hacerla más eficaz. Ello, no obstante, no debe ocultar que los datos sociológicos apuntados revelan que se está produciendo un cambio y que los representantes elegidos por el pueblo español deben poner los medios necesarios para que este cambio se realice a través de los cauces constitucionales, legales y democráticos.

\section{REFERENCIAS BIBLIOGRÁFICAS}

- Aguiar de Luque, L. (1997). Democracia directa y Estado constitucional. Madrid: Edersa.

- Aguiar de Luque, L. (1986). Participación política y referéndum. Aspectos teóricos y constitucionales. Revista de Derecho Público. Núm. 102. Madrid.

- Álvarez Conde, E. (2013). El derecho Constitucional y la Crisis. Revista de Derecho Político, Madrid, $\mathrm{n}^{0} 88$.

- Álvarez Conde, E. (2010). Consultas populares. Revista para la mejora de la calidad democrática, $\mathrm{n}^{0} 1$, Gobierno de Aragón.

- Aragón Reyes, M. (1997). Estado y democracia. El Derecho Público de finales de siglo. Una perspectiva Iberoamericana. Madrid.

- Araujo, J. (1986). El referéndum en el Sistema Constitucional español. Cuadernos de la Facultad de Derecho, 15. Palma de Mallorca. 
- Arnaldo, E. (2008). Revocatoria de mandato. Enciclopedia jurídica 20. Madrid: La Ley.

- Di Ruffia, P. (1965). Derecho Constitucional. Madrid.

- Butler, D (1978). "United Kingdom”, en Butler y Ranney (eds.)

- Butler,D.\&Austin,R.(eds.).(1978). Referendums: A Comparative Study of Practice and Theory, op. cit., 1978; Ranney, Austin, "United States", en Butler y Ranney (Eds.).

- Carbajal Iranzo, I. (2008). Democracia directa. Enciclopedia jurídica. Madrid: La Ley.

- Castellà Andreu, J. (2013). Consultas populares no referendarias en Cataluña. ¿Es admisible constitucionalmente un tertium genus entre el referéndum e instituciones de participación ciudadana?, Monografías de la RevistaAragonesa de Administración Pública, XIV. Zaragoza.

- Chiappetti, A. (1983). Plebiscito, voz en Enciclopedia del diritto, vol. XXXIII, Giuffrè, Milano.

- Denquin, J. (1976). Référendum et plébiscite. LGDJ. Paris.

- Duguit, L. (1894). Les fonctions de l'état moderne. Revue internationale de sociologie.

- García-Pelayo,M. (1984).Derecho constitucional comparado. Madrid: Alianza Editorial.

- Groppi, T. (2010). La democracia directa. El caso italiano. Ponencia para el III Seminario internacional del observatorio judicial electoral. México.

- Hamon, F. (1995). Le Referendum : Étude Comparative, Librairie générale de droit et de jurisprudence.

- Haskell, J. (2001). Direct Democracy or Representative Government? Dispelling the Populist Myth, Westview Presss.

- Kelsen, H. (1979). Teoría pura del derecho. Introducción a la ciencia del derecho, Editorial universitaria de Buenos Aires, traducción al español de la edición francesa de $1953,16^{a}$ ed.

- Lawrence, L. (2003). The politics of Direct Democracy: referendums in Global Perspective Broadview Press 20.

- López Basaguren, A. (2009). Sobre el referéndum y Comunidades Autónomas. La ley vasca de la "consulta" ante el tribunal Constitucional (consideraciones con motivo de la STC 103/2008)", REAF, núm. 9, octubre.

- López, J. (2002). El referéndum nacional consultivo sobre decisiones políticas de especial trascendencia. Cuadernos Const. De la Cátedra Fadrique Furió Ceriol n³8/39, Valencia.

- Luciani, M. (2008). El Referéndum. Cuestiones teóricas y la experiencia italiana. Revista catalana de dret públic, $n^{0} 37$.

- Mills, J.(1991). Considerations on Representative Government, Prometheus Books.

- Morel, L. (1996). "France : Towards a Less Controversial Use of the Referendum" in M Gallagher and PV Uleri (eds), The Referendum Experience in Europe. Macmillan Press.

- Olivetti, M. (2007). Los referendos en serio: la experiencia italiana, Revista Jurídica de la Universidad Autónoma de Madrid, $n^{0} 15$. Madrid: Dykinson,

- Rousseau, J. (1969). El contrato social. Traducción de Consuelo Berges, Madrid: Aguilar,

- Santamaría Pastor, J. (1985). "Comentario al artículo 92 de la Constitución española", en Garrido Falla, F. (Dir.): Comentarios a la Constitución. Madrid: Ed. Civitas

- Schmitt, C. (1970). Verfassungslehre, $5^{\mathrm{a}}$ ed., Berlin, Duncker u. Humblot.

- Tur Ausina, R. (2010). "Participación ciudadana. Oportunidad, necesidad y esencia de su regulación legal", Revista para la mejora de la calidad democrática, $n^{0} 1$, Gobierno de Aragón.

\section{PÁGINAS WEB}

- Castellá Andreu, J. Descentralización política y democracia en España. La ley catalana de consultas populares por la vía de referéndum, un intento frustrado de ampliar los derechos de participación en el plano autonómico. Disponible

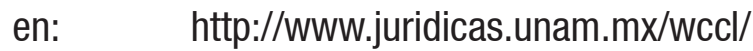
ponencias/8/132.pdf (Consultado julio de 2013)

- García Laguardia, J. El referéndum, Disponible en: http://www.mercaba.org/FICHAS/Capel/ referendum.htm (Consultado julio de 2013). 